\title{
Professionalising Primary School Teachers in Guiding Inquiry-Based Learning
}

\author{
Martina S. J. van Uum ${ }^{1}$ (D) $\cdot$ Marieke Peeters $^{2} \cdot$ Roald P. Verhoeff $^{3}$ \\ Published online: 13 February 2019 \\ (C) The Author(s) 2019
}

\begin{abstract}
This paper reports a pretest-posttest study about the impact of a teacher professional development (TPD) programme on primary school teachers' knowledge of and attitude towards inquiry-based learning. A pedagogical framework of inquiry phases and domains of scientific knowledge combined with hard and soft scaffolds formed the basis for the TPD programme. A total of 59 teachers were divided between the experimental group, which participated in the TPD programme, and a control group. We measured the teachers' subject matter knowledge (SMK) of the conceptual, epistemic, social, and procedural domain before and after the TPD programme by means of different questionnaires. In addition, we measured their knowledge of how to support their pupils during the inquiry process (PCK) and their attitude towards inquiry-based learning. The results show that our TPD programme improved teachers' conceptual and social SMK, PCK, and attitude. Our study implicates that scaffolding different domains of scientific knowledge during the inquiry cycle is a valuable component of TPD in inquiry-based learning.
\end{abstract}

Keywords Inquiry-based science education · Primary school teachers · Teacher professional development programme $\cdot$ Inquiry phases $\cdot$ Domains of scientific knowledge $\cdot$ Hard and soft scaffolds

Electronic supplementary material The online version of this article (https://doi.org/10.1007/s11165-0199818-z) contains supplementary material, which is available to authorized users.

Martina S. J. van Uum

martinavanuum@hotmail.com

1 Science Education Hub Radboud University, PO Box 9010, Internal postal box 77, 6500 GL Nijmegen, the Netherlands

2 Teacher College of Education for Primary School, HAN University of Applied Sciences, Kapittelweg 35, 6525 EN Nijmegen, the Netherlands

3 Freudenthal Institute for Science and Mathematics Education, Utrecht University, PO Box 85170, 3508 AD Utrecht, the Netherlands 


\section{Introduction}

In the past decades, there has been growing attention to inquiry-based science education (IBSE; Minner et al. 2010). IBSE improves scientific knowledge and attitudes of pupils, and motivates them as they enjoy active learning (Braund and Driver 2005; Gibson and Chase 2002; Murphy and Beggs 2003; Schroeder et al. 2007). Instead of top-down instruction, open IBSE can be viewed as a bottom-up approach, in which pupils formulate their own research question and design and conduct an investigation to answer the question (Windschitl 2003). This does not imply that teachers only observe their pupils. On the contrary, they have an important role in facilitating inquiry-based learning and scaffolding the knowledge and skills of their pupils (Van Uum et al. 2016, 2017). Unfortunately, teachers are often unfamiliar with this way of teaching and learning, as they lack confidence in their own scientific knowledge and ability to teach science (Harlen and Holroyd 1997; Murphy et al. 2007b). In addition, they experience difficulties in guiding their pupils during the inquiry process (Yoon et al. 2012; Zion et al. 2007).

Primary schools in the Netherlands are obliged to include IBSE in the curriculum in 2020 (Techniekpact 2013). As teachers experience difficulties guiding the inquiry process, we decided to develop a professionalisation programme for them. This article describes a pretest-posttest control group study about the effects of the teacher professional development (TPD) programme focused on a pedagogical framework of inquiry phases and domains of scientific knowledge combined with scaffolds. We addressed primary school teachers' scientific content knowledge, pedagogical knowledge of, and attitude towards inquiry-based learning. The paragraphs hereafter clarify our view on inquiry-based learning and elaborate the pedagogical framework and scaffolds that formed the basis for our TPD programme.

In a previous study, we developed a pedagogical framework for teachers to support the inquiry process of their pupils (Van Uum et al. 2016). The framework includes the seven phases of inquiry of Van Graft and Kemmers (2007): (1) introducing, and (2) exploring the theme of inquiry, (3) designing, and (4) conducting an investigation, (5) drawing a conclusion, 6) presenting the investigation, and (7) deepening/broadening of understanding (e.g. thinking about the implications of the results for society). In addition, based on research about science learning, science education, and the nature of science (Duschl 2008), scientific literacy (Durant 1993), and inquiry-based science teaching (Furtak et al. 2012), we distinguished four important domains of scientific knowledge to address during inquiry-based learning: the conceptual, epistemic, social, and procedural domain. The conceptual domain refers to concepts, such as gravity and electricity. Understanding the nature of science and the way scientific knowledge is generated, is part of the epistemic domain. Asking questions and drawing conclusions are considered procedures. Finally, the social domain indicates collaboration within a research project and communication about the research with scientists and the general public (Duschl 2008; Furtak et al. 2012).

As it was unclear how to combine the different phases of inquiry and domains of scientific knowledge to support pupils' inquiry process, we investigated on which domains of scientific knowledge teachers should focus to optimally guide their pupils' investigations. We found, for example that addressing the procedural domain in the phase of conducting the investigation supported pupils' data collection, and that addressing the social domain in the presentation phase of inquiry facilitated their research presentations. These important combinations of domains of scientific knowledge and phases of inquiry formed the basis for our pedagogical framework (Van Uum et al. 2016). 
Although the framework provided guidelines for teachers to address specific domains of scientific knowledge in each phase of inquiry, it lacked tools or materials to implement these interventions consistently. As research suggests that teaching materials can contribute to teachers' understanding and implementation of an open inquiry process (Van der Valk and De Jong 2009), we decided to use these to support the implementation of our pedagogical framework. In correspondence with the research of Saye and Brush (2002), we developed hard scaffolds (concrete aids, prepared in advance) and soft scaffolds (teacher support, provided after pupils' questions or after observing their difficulties to proceed with their investigation) in a subsequent study (Van Uum et al. 2017). An example of a hard scaffold is the question machine that supported the formulation of research questions by presenting different criteria that pupils used to judge and improve their research questions. A soft scaffold, for example is referring to a hard scaffold with which pupils can solve their own problems. In the current study, the pedagogical framework and scaffolds were used to improve teachers' knowledge and attitude towards inquiry-based learning.

This paper reports a pretest-posttest study in which we investigated whether and to what extent the TPD programme based on inquiry phases and domains of scientific knowledge (Van Uum et al. 2016) combined with hard and soft scaffolds (Van Uum et al. 2017) contributed to primary school teachers' knowledge of and attitudes towards IBSE. The current study complements the previous study (Van Uum et al. 2017) by investigating the quantitative value of TPD on inquiry-based learning combined with qualitative perceptions on changes in knowledge and attitude. Prior to presenting our method and results, we will clarify the theoretical framework and design of the programme.

\section{Theoretical Framework}

As teachers experience deficits in their own content knowledge, and their ability and confidence to guide inquiry-based learning (Harlen and Holroyd 1997; Murphy et al. 2007b; Yoon et al. 2012; Zion et al. 2007), we focused on increasing teachers' subject matter knowledge (SMK), their pedagogical content knowledge (PCK), and their attitude towards (teaching) the content (Rohaan et al. 2010). In the following paragraphs, the teacher knowledge components and attitude will be explained and linked to the domains of scientific knowledge and phases of inquiry combined with scaffolds that we used as a base for our TPD programme.

SMK includes knowledge regarding the content that teachers want to address, such as the concepts of electricity or temperature, their perception of this content, and their procedural knowledge (Rohaan et al. 2010). In the current study, we divided SMK into four domains of scientific knowledge that we used in our pedagogical framework (Van Uum et al. 2016). In the SMK of the conceptual domain, we elaborated the relations between the concepts of "perception and action". We chose these concepts because they were part of a successful inquiry-based lesson module developed by Science Education Hub Radboud University (Peeters et al. 2014). The epistemic SMK refers to an understanding of the nature of science (NOS; National Research Council 1996; National Science Teachers Association 2000). We selected three components: the tentative nature of scientific knowledge, the need for creativity, and the difference between observations and inferences when generating scientific knowledge (Khishfe and Abd-El-Khalick 2002). In the SMK of the procedural domain, we included scientific procedures, such as formulating a research question and drawing a conclusion (Peeters et al. 2014; Zion et al. 2007). Finally, elements of collaboration (Johnson and Johnson 2009; Schroeder et al. 2007) and effective communication (Elizabeth et al. 2012; 
Mercer et al. 2004) were included in the social SMK. To elaborate understanding of research presentations, we combined the phases of inquiry of Van Graft and Kemmers (2007) with general content of research articles, such as an introduction and a discussion (Alexandrov and Hennerici 2013). To improve teachers' understanding of each domain of scientific knowledge, we used hard scaffolds that were developed in a previous study (Van Uum et al. 2017). The hard scaffolds will be described in the paragraphs about the design of the TPD programme.

PCK refers to the interaction of content knowledge and knowledge about ways of teaching (Shulman 1987; Van Driel et al. 1998). It includes knowledge of teaching goals, pupils' misunderstandings, and elaboration of pupils' understanding regarding concepts, such as perception and action (Rohaan et al. 2010). Supporting pupils improves their achievements during inquiry-based learning (Alfieri et al. 2011). Alfieri et al. conducted two meta-analyses and compared assisted discovery with other forms of instruction, such as unassisted discovery and explicit instruction. They concluded that assisted discovery contributed the most to improvements in pupils' achievements. Alfieri et al. recommended using scaffolding to support pupils during the inquiry process. A scaffold is a framework to support the construction of a building. In education, the term refers to a temporary support that is contingent to pupils' needs and can be faded by gradually transferring responsibility of the learning process to the pupils (Lajoie 2005; Smit et al. 2013; Van de Pol et al. 2014). Several studies suggest that pupils' difficulties within the inquiry process can be overcome by scaffolding their conceptual knowledge and understanding of the inquiry process (Saye and Brush 2002; Simons and Klein 2007; Van Uum et al. 2017; Zion et al. 2007). Saye and Brush (2002), for example observed that the hard scaffolds in their study reduced the need for soft scaffolding, although soft scaffolding remained an important teaching strategy to support pupils during the inquiry process. As a combination of hard and soft scaffolds can improve pupils' scientific understanding (Van Uum et al. 2017), teachers should address both during inquiry-based learning. The current study contributes to these findings by addressing the implementation of both hard and soft scaffolds to improve teachers' understandings of learning goals for each phase of inquiry, pupils' (mis)conceptions and difficulties with the domains of scientific knowledge, and ways to elaborate pupils' understandings.

In addition to SMK and PCK, a positive teacher attitude towards IBSE should be stimulated to increase the amount of inquiry-based science in primary school classrooms (Harlen and Holroyd 1997). TPD can improve attitude towards science by explicitly focusing on different components of attitude combined with inquiry-based learning (Van Aalderen-Smeets and Walma van der Molen 2015). In our TPD programme, we divided attitude into an affective, cognitive, and perceived control component to address the joy, importance of, and confidence in teaching IBSE (Van Aalderen-Smeets and Walma van der Molen 2013). According to Van Aalderen-Smeets and Walma van der Molen, these components influence teachers' intention to change their behaviour. Therefore, we included intentional behaviour as a result of changes in attitudes. We expected that understanding the hard scaffolds would contribute to their SMK, and that implementing the hard and soft scaffolds would improve their PCK and attitude towards IBSE.

\section{Design of the TPD Programme}

To improve teachers' SMK, PCK, and attitude regarding inquiry-based learning, our programme included six components that have been reported to be essential for TPD: 
(1) focus, (2) active and inquiry-based learning, (3) collaborative learning, (4) duration and sustainability, (5) coherence, and (6) school organisational conditions (Van Driel et al. 2012). The component "focus" addresses the subject matter knowledge, pedagogical content knowledge, and attitude of the teachers. In addition to a specific focus, it is important to include active and inquiry-based learning with authentic elements (Niemi and Nevgi 2014), such as analysing and evaluating pupils' products from classroom practice. Collaborative learning addresses the exchange of ideas and activities to be used in classroom practice (Van Driel et al. 2012). It is crucial to stimulate collaboration and reflection on inquiry-based instruction (Murphy et al. 2015), as it can improve teachers' self-efficacy and inquiry instruction (Lotter et al. 2018). Although duration and sustainability of professional development programmes are important according to teachers who participated in TPD (Murphy et al. 2015), the ideal duration of an intervention is difficult to determine (Van Driel et al. 2012). Coherence refers to the importance of consistency within a TPD programme, the connection with classroom practice (Lotter et al. 2018) and with school policies within a region or country. Finally, school organisational conditions influencing the implementation of IBSE inside schools (Van Driel et al. 2012) are, for

Table 1 Overview of important components of the TPD programme

\begin{tabular}{|c|c|}
\hline Component & Activities \\
\hline Focus & $\begin{array}{l}\text { - Discussing the phases of inquiry combined with essential domains of scientific } \\
\text { knowledge in each course meeting and doing exercises and activities to improve } \\
\text { understanding of the scaffolds connected to these phases and domains. }\end{array}$ \\
\hline $\begin{array}{l}\text { Active } \\
\text { inquiry-based } \\
\text { learning }\end{array}$ & $\begin{array}{l}\text { - Watching and analysing videos and pupils' products (theory and classroom practice). } \\
\text { - Reading and reflecting on a book chapter about inquiry-based learning and } \\
\text { perception and action. } \\
\text { - Doing exercises that can be transferred to participants' own classrooms. } \\
\text { - Guiding an IBSE project in participants' own classrooms. }\end{array}$ \\
\hline $\begin{array}{l}\text { Collaborative } \\
\text { learning }\end{array}$ & $\begin{array}{l}\text { - Developing lesson plans and evaluating classroom experiences with other } \\
\text { participants. } \\
\text { - Exchanging opinions and reflections in group assignments during course meetings. } \\
\text { - Providing and receiving feedback on their inquiry-based lesson module, exchanging } \\
\text { ideas and experiences, and asking and answering each other's questions via an } \\
\text { online platform. }\end{array}$ \\
\hline $\begin{array}{l}\text { Duration and } \\
\text { sustainability }\end{array}$ & $\begin{array}{l}\text { - Participating in five course meetings (about } 12.5 \mathrm{~h} \text { ). } \\
\text { - Doing homework assignments after each meeting and preparing lessons } \\
\text { (about } 25 \mathrm{~h} \text { ). } \\
\text { - Implementing } 10-12 \text { lessons in participants' own classrooms (about } 7.5-15 \mathrm{~h} \text { ). } \\
\text { - Possibility to participate in follow-up professionalisation via the Winterschool of Science } \\
\quad \text { Education Hub Radboud University. }\end{array}$ \\
\hline Coherence & $\begin{array}{l}\text { - Discussing and doing exercises in each course meeting to understand the } \\
\text { pedagogical framework and scaffolds, and implementing these activities and } \\
\text { scaffolds in participants' own classrooms after each course meeting. } \\
\text { - Evaluating classroom experiences in each subsequent meeting. } \\
\text { - Discussing the agreement between the government, educational institutes, and } \\
\text { companies in the Netherlands to address IBSE in all primary schools by the } \\
\text { year } 2020 \text { (Techniekpact 2013). }\end{array}$ \\
\hline $\begin{array}{l}\text { School } \\
\text { organisational } \\
\text { conditions }\end{array}$ & $\begin{array}{l}\text { - Discussing school organisational conditions that influence the implementation } \\
\text { of inquiry-based learning, such as availability of time and resources, and } \\
\text { acknowledgement of the importance of the innovation by all the teachers } \\
\text { included (Ely 1990; Fullan 2007). } \\
\text { - Exchanging ideas about how to stimulate inquiry-based learning and to promote } \\
\text { a positive attitude of the teachers in participants' own schools. }\end{array}$ \\
\hline
\end{tabular}


example availability of time and resources, and acknowledgement of the importance of the innovation by all the teachers involved (Ely 1990; Fullan 2007). In Table 1, the components described in the study of Van Driel et al. are connected to specific activities in our TPD programme.

As the component "focus" addressed the core of our TPD programme, it will be elaborated here. The focus included increasing the SMK, PCK, and attitude of primary school teachers towards IBSE by means of a pedagogical framework of inquiry phases and domains of scientific knowledge combined with scaffolds. In Table 2, for each combination of inquiry phase and domain of scientific knowledge, a hard scaffold is provided. These hard scaffolds were developed in previous studies (Van Uum et al. 2016, 2017) to improve pupils' understanding of and ability to proceed with an inquiry process, and were used in the current study to improve teachers' knowledge and attitude towards inquiry-based learning. The learning goals regarding teachers' SMK and PCK for each hard scaffold are described in Table 2. The learning goals regarding teachers' attitude were similar for each hard scaffold: to understand the importance of each hard scaffold, to feel confident when implementing the hard scaffold in classroom practice, and to appreciate pupils' ability to use the hard scaffold to design and conduct their own investigations.

In each of the five course meetings of the TPD programme (about $2.5 \mathrm{~h}$ each), we addressed one or more phases of inquiry combined with domains of scientific knowledge and corresponding scaffolds. In meeting 1, we explained the general structure of the framework. Subsequently, we focused on the first inquiry phase "introduction" combined with hard scaffolds about the epistemic domain of scientific knowledge. In meeting 2, we explained the second inquiry phase "exploration" and scaffolds related to the conceptual domain of scientific knowledge. Epistemic, social, and procedural scaffolds were addressed in the third meeting combined with the inquiry phase "designing the investigation". In the fourth meeting, we paid attention to the inquiry phases "conducting the investigation" and "conclusion" combined with procedural and epistemic scaffolds. Finally, in the fifth meeting, a social scaffold was used in the "presentation" phase of inquiry and the "deepening/broadening" phase was explained. In Online Resource 1, the content of each course meeting is described.

In a previous study (Van Uum et al. 2017), soft scaffolds were developed to provide pupils with contingent support connected to the needs of the pupils (Van de Pol et al. 2014). The soft scaffolds were "(1) refer to a hard scaffold, and (2) provide examples or explanations regarding the hard scaffold" (Van Uum et al. 2017, p. 2468). These soft scaffolds were discussed in the first three meetings of the TPD programme, and applied by teachers in their own classrooms when guiding inquiry phases $1-3$. From the fourth TPD meeting onwards, the model of soft scaffolding of Van de Pol et al. was discussed with the teachers, including the subsequent steps (diagnostic strategy, check diagnose, contingent support, and check understanding). These steps were practised and applied by teachers when guiding inquiry phases 4-7 in their own classrooms.

Social constructivist and situated learning principles were used to construct learning activities for the participants of our course (Aydeniz and Brown 2010). In accordance with social constructivism, participants of the TPD programme retrieved prior knowledge and constructed new knowledge in a social context (Bransford et al. 1999). They, for example discussed their views with others and connected hands-on with minds-on activities (Bleicher and Lindgren 2005) related to the hard scaffolds. Situated learning was applied to achieve a meaningful context (Aydeniz and Brown 2010) by combining course meetings with 


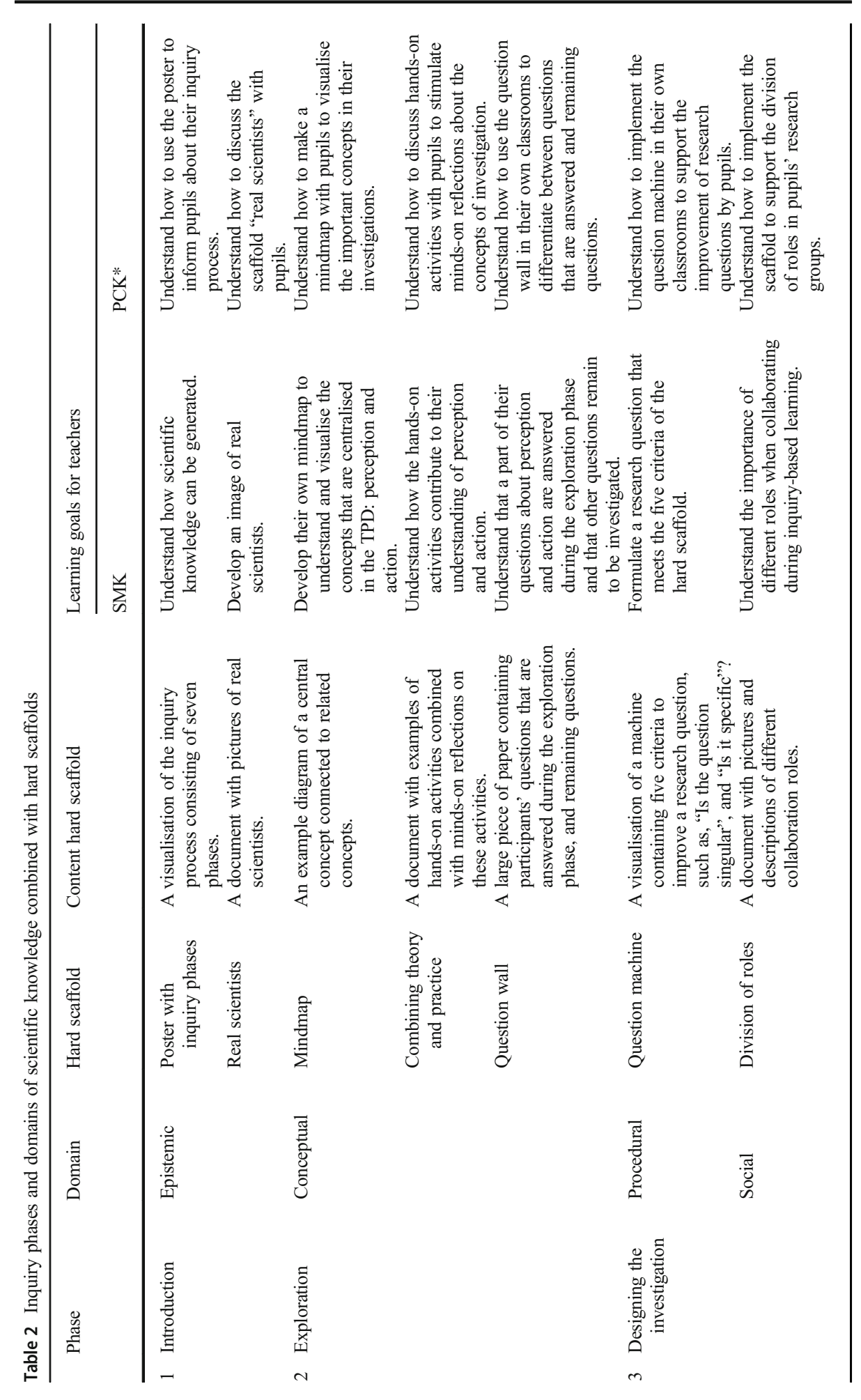




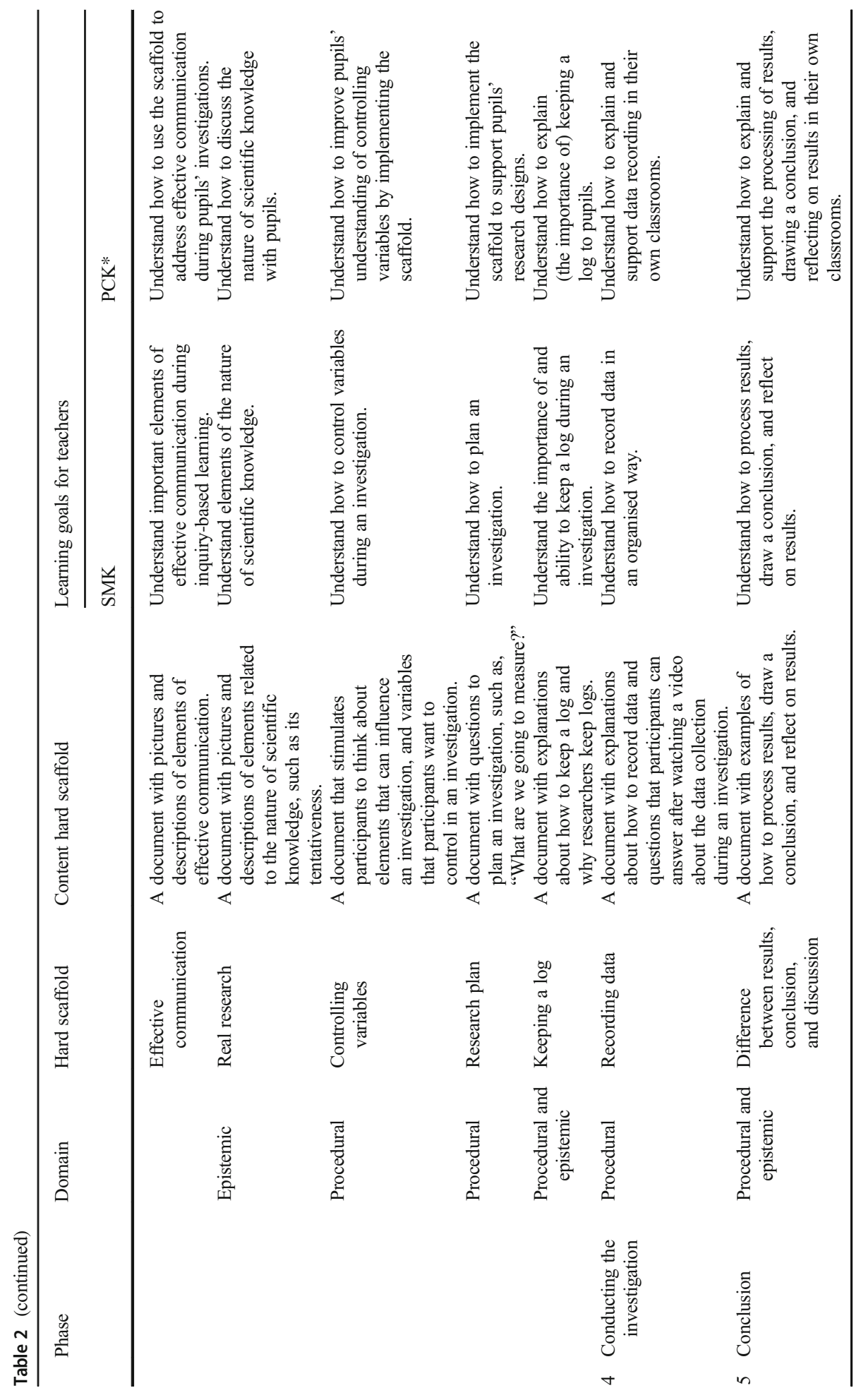




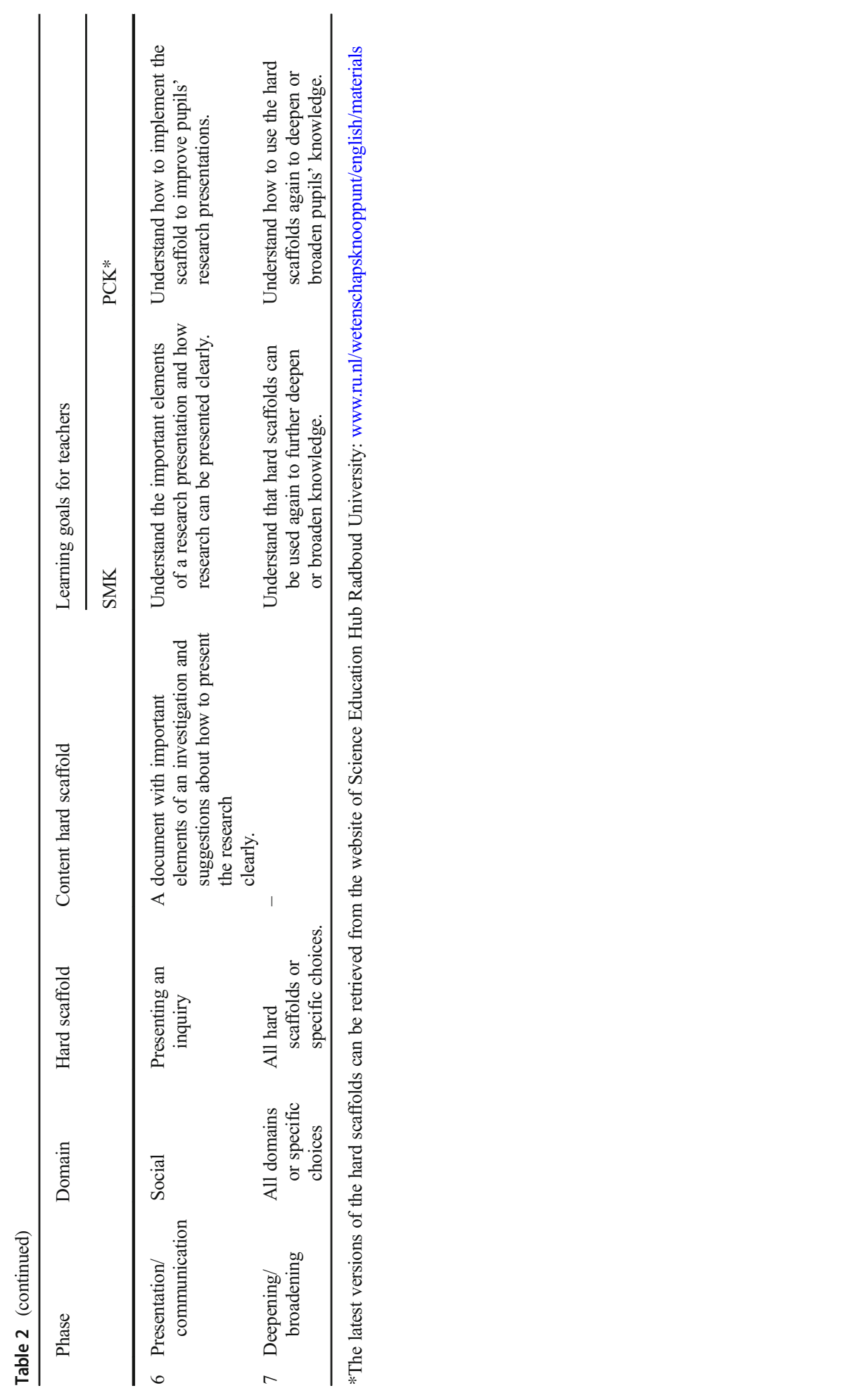


implementing the hard and soft scaffolds in participants' own classrooms. In Table 3, the general structure of each course meeting is described including the focus on SMK, PCK, and/ or attitude for each learning goal and learning activity.

Table 3 General structure of each course meeting of the TPD programme

\begin{tabular}{|c|c|c|}
\hline Learning goals & Learning activities & Focus \\
\hline $\begin{array}{l}\text { Understanding the general structure } \\
\text { of the pedagogical framework } \\
\text { combined with hard and soft } \\
\text { scaffolds. }\end{array}$ & $\begin{array}{l}\text { Listening to an explanation about the framework } \\
\text { (course meeting 1). Retrieving knowledge by } \\
\text { asking and answering questions about it } \\
\text { (course meetings 2-5). }\end{array}$ & $\begin{array}{l}\text { SMK } \\
\text { PCK }\end{array}$ \\
\hline \multirow{4}{*}{$\begin{array}{l}\text { Understanding the content of each } \\
\text { inquiry phase combined with } \\
\text { domains of scientific knowledge } \\
\text { and corresponding hard and } \\
\text { soft scaffolds. }\end{array}$} & $\begin{array}{l}\text { Watching a classroom video about each } \\
\text { inquiry phase. }\end{array}$ & PCK Attitude \\
\hline & $\begin{array}{l}\text { Discussing the content on the hard scaffold(s) } \\
\text { (Van Uum et al. 2017). Watching videos and } \\
\text { making exercises that are part of the hard } \\
\text { scaffold(s). }\end{array}$ & SMK \\
\hline & $\begin{array}{l}\text { Taking part in activities that participants can } \\
\text { use in their own classrooms, such as the } \\
\text { introduction activity "balancing a tray with } \\
\text { drinks while running a trail" (see Online } \\
\text { Resource 1), to improve understanding of a } \\
\text { domain of scientific knowledge and/or a phase } \\
\text { of inquiry, and to experience and enjoy } \\
\text { inquiry-based learning hands-on. }\end{array}$ & $\begin{array}{l}\text { SMK } \\
\text { PCK Attitude }\end{array}$ \\
\hline & $\begin{array}{l}\text { Determining learning goals for pupils in each } \\
\text { inquiry phase, addressing pupils' } \\
\text { (mis)conceptions related to the domain of } \\
\text { scientific knowledge that the scaffold focused } \\
\text { on and discussing the implementation of each } \\
\text { hard scaffold in classroom practice. Practising } \\
\text { soft scaffolding (Van de Pol et al. 2014) in } \\
\text { course meetings } 4 \text { and 5. }\end{array}$ & PCK \\
\hline $\begin{array}{l}\text { Understanding how to prepare } \\
\text { one or more lessons for the } \\
\text { inquiry-based lesson module. }\end{array}$ & $\begin{array}{l}\text { Using the content of each course meeting to } \\
\text { compose a lesson plan in pairs and finishing } \\
\text { it as a homework assignment. }\end{array}$ & PCK \\
\hline $\begin{array}{l}\text { Being able and confident to guide } \\
\text { the inquiry phase(s) that is(are) } \\
\text { centralised in the specific course } \\
\text { meeting in teachers' own } \\
\text { classrooms and enjoying pupils' } \\
\text { excitement to design and } \\
\text { conduct their own inquiries. }\end{array}$ & $\begin{array}{l}\text { Guiding the specific phase(s) of inquiry including } \\
\text { the use of scaffolds in teachers' own classrooms } \\
\text { and experiencing the reaction of the pupils. }\end{array}$ & PCK Attitude \\
\hline $\begin{array}{l}\text { Being able to reflect on their } \\
\text { acquired knowledge and } \\
\text { improved attitude. }\end{array}$ & $\begin{array}{l}\text { Filling in a reflection form each time participants } \\
\text { guided an inquiry-based lesson in their own } \\
\text { classrooms. Describing whether and how the } \\
\text { TPD programme contributed to their } \\
\text { knowledge and attitude in order to teach } \\
\text { each lesson. }\end{array}$ & $\begin{array}{l}\text { SMK } \\
\text { PCK } \\
\text { Attitude }\end{array}$ \\
\hline $\begin{array}{l}\text { Understanding how to improve } \\
\text { the implementation of the } \\
\text { inquiry-based lesson module } \\
\text { in teachers' own classrooms. }\end{array}$ & $\begin{array}{l}\text { Exchanging and evaluating classroom } \\
\text { experiences, giving suggestions for each other's } \\
\text { lessons, and developing ideas for subsequent } \\
\text { lessons of the lesson module (course } \\
\text { meetings 2-5). }\end{array}$ & PCK \\
\hline $\begin{array}{l}\text { Being prepared for the } \\
\text { subsequent course meeting. }\end{array}$ & $\begin{array}{l}\text { Doing homework assignments, such as reading } \\
\text { an article about inquiry-based learning or } \\
\text { watching classroom videos. }\end{array}$ & $\begin{array}{l}\text { SMK } \\
\text { PCK Attitude }\end{array}$ \\
\hline
\end{tabular}




\section{Method}

\section{Participants}

To inform potential participants about our TPD programme, we described the programme in the newsletter of Science Education Hub Radboud University. In addition, a letter was sent to schools in the region of Science Education Hub Radboud University and each school was phoned to provide further information. We asked the principal of each school whether there were teachers in his or her school that had little experience with IBSE and were interested in participating in our TPD programme. We informed potential participants that two groups would be formed to which participants would be assigned without being able to choose for a particular group, due to the research connected to the TPD programme: a group that would start the TPD programme in the spring and another group that would start the TPD programme in the autumn of the same year. All teachers who subscribed to our TPD programme were included and had a maximum experience of guiding one inquiry-based lesson in their own classrooms. This resulted in the enrolment of 59 teachers from 25 different schools.

Since the TPD programme focused on teaching upper primary school pupils, we asked participants to describe the amount of experience they had with teaching these pupils, in addition to their total amount of teaching experience. Furthermore, we asked them about the pedagogy they used to teach their pupils: traditional and focused on the whole class, or innovatory, such as Jenaplan and Dalton in which pupils work together in small groups or independently with responsibility for their own learning. Finally, we asked participants whether they taught pupils with high performance scores in a separate classroom, because these groups of pupils are usually smaller than the average classroom of pupils. The information regarding the different variables was used to match participants and form two equal groups: an experimental group (30 teachers) and a control group (29 teachers).

The experimental group consisted of 25 women and 5 men. Their average age was 46 $(S D=11.18)$. The control group consisted of 20 women and 9 men with an average age of 42 years and 6 months $(S D=9.96)$. In Table 4 , the relevant data of each group are presented.

The experimental and control group were comparable on gender, $\chi^{2}(1)=1.68, p=.233$, school didactics, $\chi^{2}(1)=.52, p=.589$, years of teaching experience, $\chi^{2}(1)=1.14, p=.333$, and years of experience teaching upper primary school pupils, $\chi^{2}(1)=1.36, p=.295$. Since $50 \%$ of the cells of the following three variables were less than 5, we used Fisher's exact test to determine whether these variables were comparable between the experimental and control group: age $(p=.237)$, amount of education combined with research experience $(p=.693)$, and teaching talented pupils $(p=.671)$.

\section{Research Design and Procedure}

To measure the effects of the TPD programme on teachers' knowledge and attitude, we used a pretest-posttest control group design. During 4 months, the experimental group took part in the TPD programme. At the end of the first TPD course meeting, participants were asked to start implementing lessons of the inquiry-based lesson module in their own classrooms parallel to the different TPD course meetings. The control group did not receive any training within that time period, since they would participate in the TPD programme after the current study had been conducted. One month before and after the professionalisation of the experimental group, both the experimental and control group filled in an online questionnaire in which 
Table 4 Characteristics of the experimental and control group

\begin{tabular}{|c|c|c|c|}
\hline Variable & Category & Experimental group $*(n=30)$ & Control group* $(n=29)$ \\
\hline \multirow[t]{2}{*}{ Gender } & Woman & 83.3 & 69.0 \\
\hline & Man & 16.7 & 31.0 \\
\hline \multirow[t]{3}{*}{ Age } & $<30$ & 16.7 & 17.2 \\
\hline & $30-55$ & 60.0 & 75.9 \\
\hline & $>55$ & 23.3 & 6.9 \\
\hline \multirow{4}{*}{$\begin{array}{l}\text { Highest level of education } \\
\text { combined with experience } \\
\text { with research }\end{array}$} & $\begin{array}{l}\text { Bachelor's degree, no } \\
\text { research experience }\end{array}$ & 53.3 & 41.4 \\
\hline & $\begin{array}{l}\text { Bachelor's degree, } \\
\text { research experience }\end{array}$ & 33.3 & 34.5 \\
\hline & $\begin{array}{l}\text { Master's degree, higher } \\
\text { vocational education }\end{array}$ & 10.0 & 17.2 \\
\hline & $\begin{array}{l}\text { Master's degree, } \\
\text { university }\end{array}$ & 3.3 & 6.9 \\
\hline \multirow[t]{2}{*}{ School didactics } & Traditional & 60.0 & 69.0 \\
\hline & $\begin{array}{l}\text { Innovatory, such as } \\
\text { Dalton, Montessori. }\end{array}$ & 40.0 & 31.0 \\
\hline \multirow{2}{*}{$\begin{array}{l}\text { Teaching talented pupils } \\
\text { with high performance in } \\
\text { a separate classroom }\end{array}$} & Yes, teaching this class & 13.3 & 6.9 \\
\hline & No, not teaching this class & 86.7 & 93.1 \\
\hline \multirow[t]{2}{*}{ Years of teaching experience } & $0-5$ years & 13.3 & 24.1 \\
\hline & More than 5 years & 86.7 & 75.9 \\
\hline \multirow{2}{*}{$\begin{array}{l}\text { Years of experience teaching } \\
\text { upper primary school pupils }\end{array}$} & $0-5$ years & 33.3 & 48.3 \\
\hline & More than 5 years & 66.7 & 51.7 \\
\hline
\end{tabular}

*The percentages of the group characteristics are provided

measurement instruments about SMK, PCK, and attitude towards IBSE were included. These instruments will be described hereafter. Participants needed about 45 minutes to complete the questionnaire. In the results section of this article, we will explain that the teachers in the experimental and control group acquired comparable results on the pretests, but differed in their results on most of the posttests. In addition, directly after the fifth course meeting, participants of the experimental group were asked questions about their perceived changes in SMK, about contributing elements of the TPD to their SMK, PCK, and attitude, and about their intentions to sustain IBSE in classroom practice (see Table 5).

\section{Measurement Instruments}

The different measurement instruments used in the current study are described hereafter and summarised in Table 5. To measure the SMK, PCK, and attitude of the participants in our study, we used a mixed methods approach to elaborate the educational process and to determine significant differences between pre- and posttests. We developed or selected measurement instruments to include in our questionnaire. The measurement instruments consisted of open questions and/or Likert scales ranging from 1 (totally disagree) to 5 (totally agree). The SMK was measured using tests in which participants answered questions or responded to statements about the four domains of scientific knowledge. The SMK tests consisted of open questions (conceptual SMK, social SMK, and procedural SMK) or a combination of Likert items and open questions (epistemic SMK). To measure the epistemic SMK, we selected the SUSSI instrument (Liang et al. 2008) and we used the Diet Cola test (Fowler 1990) to measure the procedural SMK. The conceptual SMK questions were 


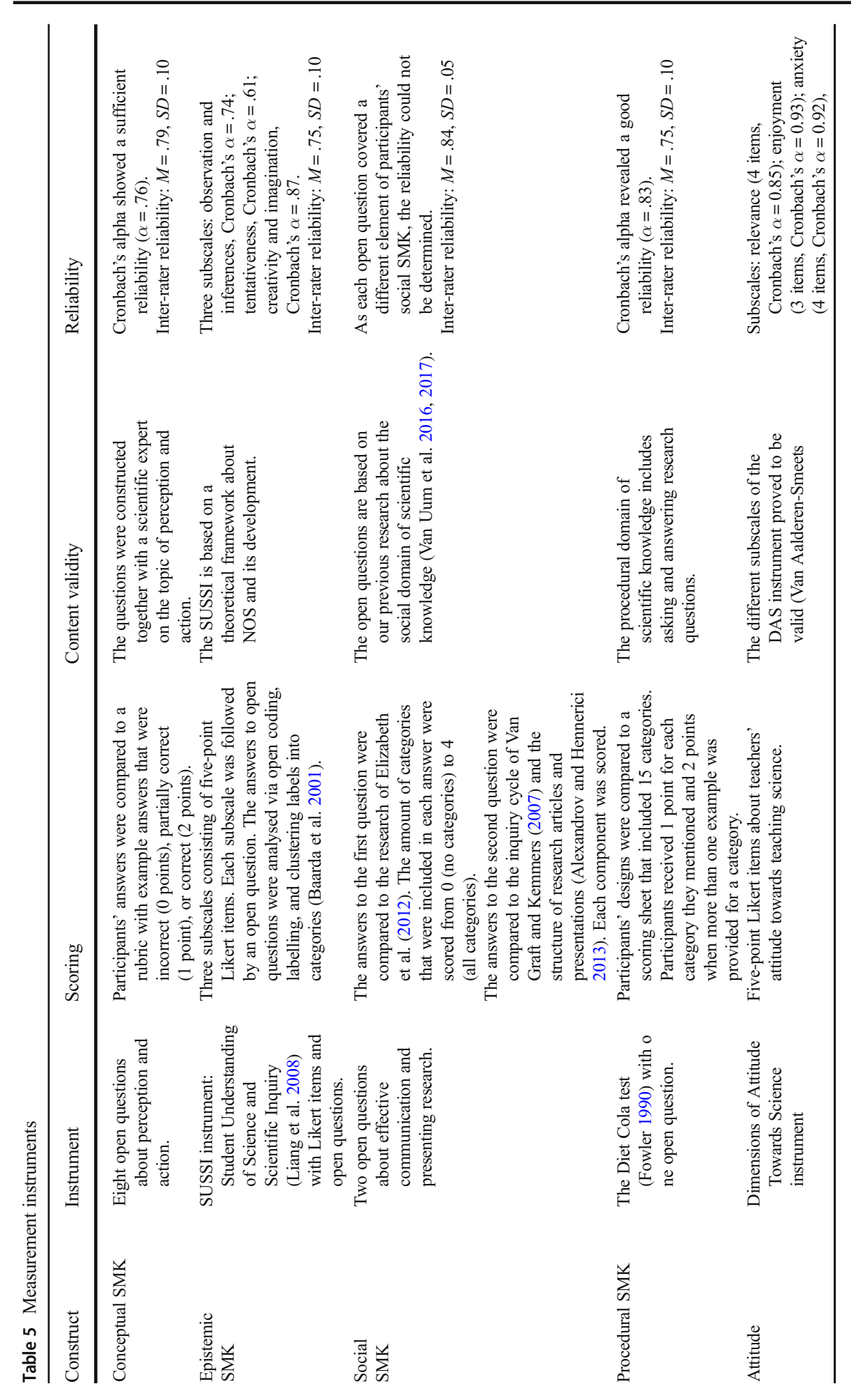




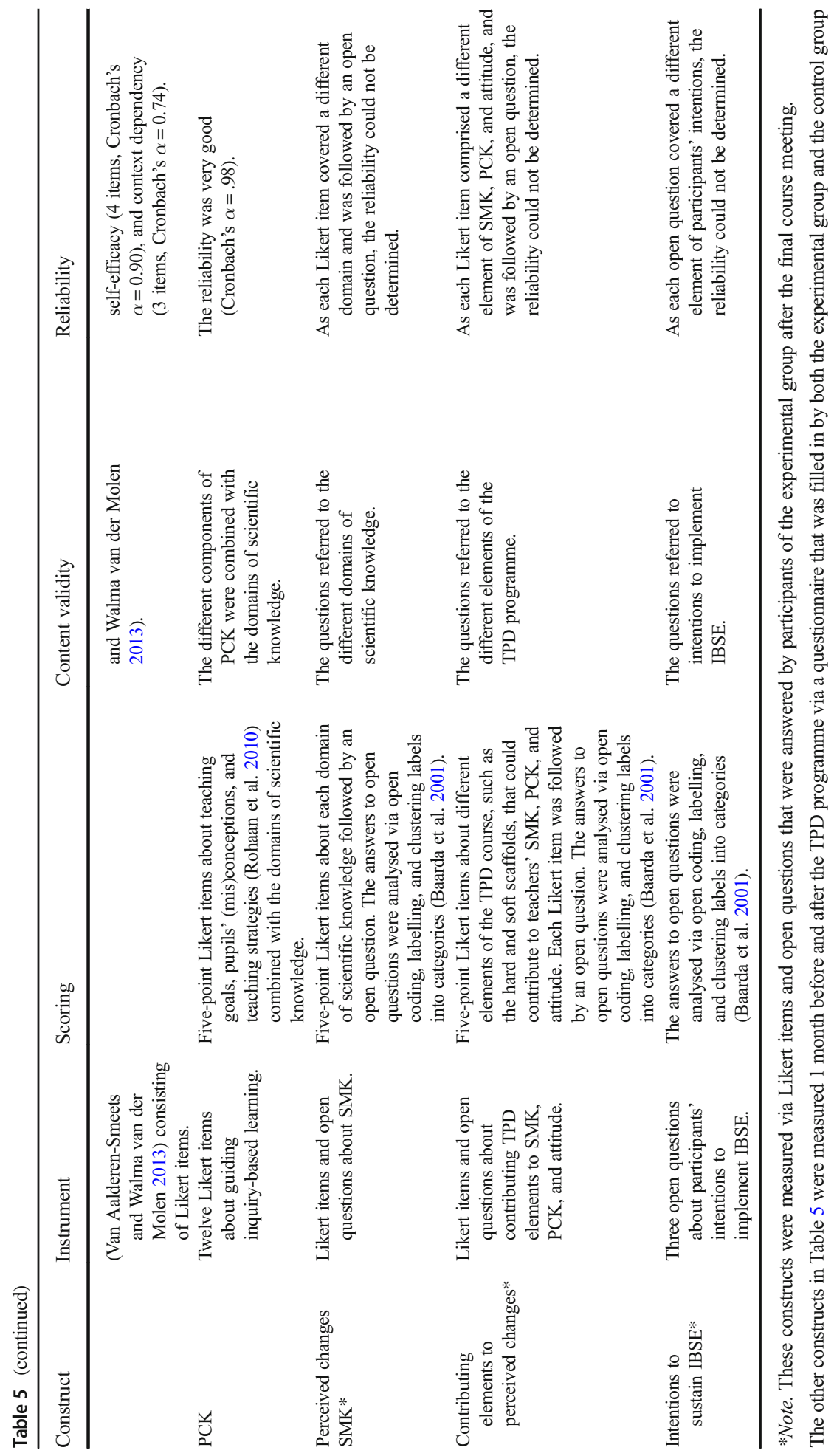


developed together with a scientific expert on the topic of perception and action, and the social SMK questions were based on our previous studies (Van Uum et al. 2016, 2017). The open questions of these tests were analysed by assigning numeric values to each response (see Table 5). To determine whether the results of these tests corresponded with the teachers' own views, participants of the experimental group were asked to respond to Likert items about their perceived changes in SMK combined with an open question to explain their answers.

Teachers' attitude was measured via Likert items of the Dimensions of Attitude Towards Science instrument (Van Aalderen-Smeets and Walma van der Molen 2013). Taking into account the available time to measure participants' PCK in addition to their SMK of the four domains of scientific knowledge and their attitude, we excluded interviews or observations as measurement instruments. Since it proved to be difficult to construct a multiple-choice test to measure PCK (Rohaan et al. 2009), we chose to measure participants' perceptions of their ability to teach inquiry-based learning via Likert items. Teachers of the experimental group were asked which elements of the TPD contributed to their SMK, PCK, and attitude via Likert items and open questions. In addition, they were asked open questions about their intention to sustain IBSE in their own classrooms.

Conceptual SMK We constructed a test of eight open questions based on the Science Education Hub Radboud University's lesson module "perception and action" (Peeters et al. 2014) together with a scientific expert on the topic of perception and action. The first question in the questionnaire focused on the working of the brain. Subsequently, different activities about perception and action were described, such as throwing an object to a target with or without looking through a small periscope. Participants were asked to apply their knowledge of the relations between perception and action by answering questions about these activities, e.g. "Why do people make more mistakes when they look through a periscope when throwing an object to a target than without the periscope?"

Epistemic SMK We have chosen the Student Understanding of Science and Scientific Inquiry (SUSSI) to measure epistemic SMK (Liang et al. 2008). The SUSSI is based on a theoretical framework about the nature of scientific knowledge and its development, and existing instruments to measure NOS. We selected subscales of the SUSSI that were consistent with literature regarding epistemic knowledge of primary school pupils (Khishfe and Abd-ElKhalick 2002). The subscale "observations and inferences" referred to understanding that prior knowledge influences the way scientists observe and interpret phenomena within their investigations. The "tentativeness" of scientific knowledge indicated understanding that scientific theories can be changed, for example when new evidence arises. Finally, the subscale "creativity and imagination" referred to knowledge of the importance of creativity when collecting, analysing, and interpreting data. For each item within a subscale, participants decided how much they agreed or disagreed with the statement. In an open question after each subscale, they explained their answers. Based on their answers to various statements that matched naïve versus informed views of NOS and scientific inquiry, we could determine teachers' epistemic SMK.

Social SMK The social knowledge was divided into (1) knowledge about collaboration and communication when designing and conducting an investigation with others, such as a group of pupils, and (2) knowledge about composing a research presentation and presenting the research to an audience, such as classmates or parents. 
Knowledge about collaboration and communication within a research group was tested with the question: "Which concepts correspond with effective communication during the collaboration within a (research) group? Write down as many concepts as possible". The word "research" was added to the question to clarify that participants answered the question within the context of inquiry-based learning. Teachers' answers were analysed by comparing them with categories of a framework on academic discussion in primary schools developed by Elizabeth et al. (2012). These categories are cooperation and collaboration, reason and logic, information and evidence, and perspectives and voice. The cooperation and collaboration category included asking questions and sharing information. In addition, we incorporated the elements of individual accountability and positive interdependence of Johnson and Johnson (2009) within this category. For example, each group member is made responsible for a component of the task, and roles, such as chairman and minutes secretary are divided. The reason and logic category of Elizabeth et al. consisted of formulating arguments and considering arguments of group members. In the category of information and evidence, knowledge and information were used to provide evidence for claims. Finally, the perspectives and voice category referred to being able to understand and respect each other's perspectives.

Knowledge about composing a research presentation and presenting the investigation was tested with the question "What should a researcher take into account when developing and giving a presentation about his or her investigation?" To select components for research presentations in primary schools, we used the phases of the inquiry cycle of Van Graft and Kemmers (2007), such as designing and conducting an investigation, combined with the general structure of research articles which are as follows: introduction, methods, results, discussion (conclusions) (Alexandrov and Hennerici 2013). Each component that was described by participants was scored. For example, citations, such as "mentioning the research question" and "explaining the different steps that were taken to conduct the investigation" matched our framework of analyses. In contrast, general communication skills, such as "eye contact" and "non-verbal communication" were excluded from the analyses of the answers to the current and previous question, because we focused on communication skills related to inquiry-based learning. In addition, concepts that could refer to more than one category, because a clear explanation was not provided, were excluded from the analyses.

Procedural SMK The knowledge of teachers regarding inquiry procedures was measured by the Diet Cola test of Fowler (1990). In the Diet Cola test, participants were asked how they would answer a research question by describing an investigation. Before the start of our TPD programme, participants were asked the question "Are bees attracted to Diet Cola? In other words: do bees like Diet Cola?" After the TPD programme, participants addressed the question "Are earthworms attracted to light? In other words: do earthworms like light?" (Adams and Callahan 1995). Participants were asked to describe the steps to take in order to answer the questions. Fowler's scoring sheet was used to categorise their answers. This sheet includes, for example the items "predicts outcome or hypothesizes", "plans to measure", "plans data collection", and "states plan for making a conclusion".

Attitude We used the Dimensions of Attitude Towards Science (DAS) instrument to measure teachers' attitude towards teaching science (Van Aalderen-Smeets and Walma van der Molen 2013). As the components "difficulty" and "gender beliefs" did not predict science teaching and were unrelated to other components according to Van Aalderen-Smeets and Walma van der Molen, we excluded these subscales from our test. The subscale "relevance" within the 
dimension "cognition" measured teachers' beliefs about the importance of science education in primary schools, e.g. "I think that science education is essential for primary school children's development". Within the "affect" dimension, the enjoyment and anxiety towards teaching science were measured. As Van Aalderen-Smeets and Walma van der Molen explained, a teacher can both enjoy and be a bit anxious towards teaching science, e.g. "Teaching science makes me enthusiastic" and "I feel nervous while teaching science". The "perceived control" domain consisted of the components "self-efficacy" and "context dependency". Selfefficacy referred to a person's beliefs in his or her own knowledge or ability to teach science, e.g. "I have enough knowledge of the content of science to teach these subjects well in primary school". Context dependency included opinions about the need for lesson modules and materials to be able to teach science, e.g. "For me, the availability of a science teaching method is decisive for whether or not I will teach science in class".

PCK A questionnaire with 12 items was developed to measure teachers' perception of their ability to guide inquiry-based learning in their own classrooms by means of five-point Likert scales. We differentiated between teaching goals, (mis)conceptions of pupils, and teaching strategies (Rohaan et al. 2010). We combined these components with the four domains of scientific knowledge (conceptual, procedural, epistemic, and social) that are part of the pedagogical framework developed in our previous study (Van Uum et al. 2016) and were used in classroom practice in a second study (Van Uum et al. 2017). For example, the PCK of the conceptual domain included the questions "I know which content goals I can address for pupils regarding the theme of perception and action", "I know which difficulties pupils encounter regarding this theme", and "I know how I can guide pupils to better understand this theme".

Perceived Changes Directly after the fifth course meeting, we asked the participants of the experimental group by means of five-point Likert scales and open questions to write down to what extent their conceptual, social, epistemic, and procedural SMK had changed by taking part in the TPD programme. In a similar way, we measured participants' opinions about the contribution of elements of the TPD to improvements in their SMK, PCK, and attitude.

Intentions to Sustain IBSE in Classroom Practice After the TPD programme, participants of the experimental group were asked three open questions in a questionnaire about their intentions to (1) guide inquiry-based projects in their classroom more often, (2) motivate their colleagues to implement inquiry-based learning, and (3) whether they had made specific appointments with their colleagues to implement IBSE as a result of the TPD.

\section{Inter-Rater Reliability of Open Questions}

To measure the inter-rater reliability of the answers to open questions of the SMK questionnaires, a sample of 30 participants was selected (15 of the experimental group and 15 of the control group). The distribution of the variables that were used to match participants between the experimental and control group was taken into account and an equal distribution of participants on these variables was achieved. In addition, another group of 10 participants was selected whose answers were used to practise the scoring by two raters. The first rater had developed and taught the TPD programme, and had composed scoring rubrics for the measurement instruments that contained open questions within the questionnaire. The second 
rater was trained by the first rater to use the scoring rubrics. After scoring the answers of five to ten participants to each question in the questionnaire, both raters discussed dissimilarities in their scoring and adjusted the scoring rubrics. Subsequently, they individually scored the answers of 30 participants. For each question, an inter-rater reliability was established. Cohen's Kappa's were calculated (Landis and Koch 1977). For each domain, the mean of the Cohen's Kappa and its standard deviation were SMK conceptual domain, $M=.79, S D=.10$, SMK epistemic domain, $M=.75, S D=.10$, SMK social domain, $M=.84, S D=.05$, and SMK procedural domain, $M=.75, S D=.10$. Subsequently, the first rater scored the remaining answers to open questions.

\section{Quantitative Analyses}

To determine whether the experimental and control group were comparable on each pretest of attitude, PCK, and SMK, we conducted one-way independent ANOVAs. The scores on the SMK, PCK, and attitude tests were translated into z-scores to conduct overall analyses. For each pre- and posttest of the measurement instruments, a z-sum score was calculated. GLM repeated measures MANOVA was used to analyse the z-sum scores of the experimental and control group before and after the TPD programme. Furthermore, the sum scores of both groups were compared by means of univariate repeated measures ANOVAs to calculate whether there were interaction effects of time and group on each variable. Subsequently, paired $t$ tests were used to calculate the differences on the pretest and the posttest for each group separately.

\section{Qualitative Analyses}

Participants' perceived changes in SMK were divided into the conceptual, epistemic, social, and procedural domain of scientific knowledge. The different TPD elements that were included in the analysis were as follows: understanding hard and soft scaffolds; implementing the inquiry-based lesson module in participants' own classroom; and the exchange of ideas, lesson preparations, and classroom experiences with other participants. For each of the TPD elements, it was determined how many participants perceived positive changes in SMK, PCK, and attitude. Furthermore, the different intentions of participants to sustain IBSE in classroom practice included guiding IBSE lesson modules more often; motivating colleagues to implement inquiry-based learning; and making appointments with their colleagues to implement IBSE in their own classrooms. For each of these components, it was determined how many participants intended to sustain IBSE in classroom practice.

Participants' perceived changes in SMK, their explanations of contributing elements of the TPD, and their intentions to continue to use IBSE in classroom practice were analysed for each variable via open coding, labelling, and clustering labels into categories (Baarda et al. 2001) and will be presented in the results section of the article.

\section{Results}

\section{Comparability of Groups}

In order to check whether the experimental and control group did not differ on the pretests of SMK, PCK, and attitude, we analysed the results of 24 participants of the experimental group 
and the results of 26 participants of the control group, due to missing variables on the questionnaires of 9 participants. By means of one-way independent ANOVAs, we established that there were no significant differences between the experimental group and the control group on the pretests of attitude, $F(1)=1.34, p=.253, \eta_{\mathrm{p}}^{2}=.03$, PCK, $F(1)=.52, p=.475$, $\eta_{\mathrm{p}}{ }^{2}=.01$, conceptual SMK, $F(1)=2.88, p=.096, \eta_{\mathrm{p}}{ }^{2}=.06$, epistemic SMK, $F(1)=.21$, $p=.652, \eta_{\mathrm{p}}^{2}=.00$, social SMK, $F(1)=.78, p=.381, \eta_{\mathrm{p}}^{2}=.02$, and procedural SMK, $F(1)=$ $1.33, p=.255, \eta_{\mathrm{p}}{ }^{2}=.03$. These results indicate that the experimental and control group were comparable on the knowledge components and their attitude towards IBSE before the experimental group participated in the TPD programme.

\section{Quantitative Results on SMK, PCK, and Attitude}

We conducted a repeated measures MANOVA with time (pretest versus posttest) as a withinsubjects factor, group (experimental versus control group) as a between subjects factor, and the different knowledge and attitude tests as dependent variables (attitude, PCK, conceptual SMK, epistemic SMK, social SMK, and procedural SMK). In Table 6, the means and standard deviations of the different variables for each group are provided.

Wilks' Lambda revealed an overall significant interaction effect of time and group, $\Lambda=.40$, $F(6,43)=10.73, p<0.001, \eta_{\mathrm{p}}{ }^{2}=.60$, which represented differences in acquired knowledge and/or improved attitude between pretest and posttest for the experimental group and the control group. Subsequent univariate repeated measures ANOVAs showed significant interaction effects of time and group on attitude, PCK, conceptual SMK, and social SMK (see Table 6). These results clarify that the improvements in attitude, PCK, conceptual SMK, and social SMK were different between the pretest and posttest for the experimental and control group. The univariate repeated measures of the epistemic SMK and procedural SMK showed no significant interaction effects of time and group (see Table 6).

Subsequently, the results on attitude, PCK, and the SMK variables were measured separately for the experimental group and control group by means of paired $t$ tests. The paired $t$ tests of the experimental group showed a significant increase between the pretest and posttest

Table 6 Descriptive statistics and repeated measures results of the experimental and control group on the knowledge and attitude variables

\begin{tabular}{|c|c|c|c|c|c|c|c|c|c|c|c|}
\hline & \multicolumn{4}{|c|}{ Experimental group* } & \multicolumn{4}{|c|}{ Control group $* *$} & & & \\
\hline & \multicolumn{2}{|l|}{ Pre } & \multicolumn{2}{|l|}{ Post } & \multicolumn{2}{|l|}{ Pre } & \multicolumn{2}{|l|}{ Post } & \multicolumn{3}{|c|}{ Interaction time and group } \\
\hline & M & $\mathrm{SD}$ & M & $\mathrm{SD}$ & $\mathrm{M}$ & SD & $\mathrm{M}$ & $\mathrm{SD}$ & $F$ & $p$ & $\eta_{\mathrm{p}}^{2}$ \\
\hline Att*** & 67.04 & 11.45 & 76.96 & 9.56 & 70.31 & 8.40 & 68.69 & 8.18 & 45.89 & $<.001$ & .49 \\
\hline PCK & 29.38 & 8.79 & 52.04 & 7.68 & 31.08 & 7.93 & 32.19 & 10.80 & 52.32 & $<.001$ & .52 \\
\hline Con & 7.83 & 1.63 & 11.04 & 2.66 & 6.85 & 2.38 & 6.58 & 2.89 & 26.34 & $<.001$ & .35 \\
\hline Epi & 36.50 & 6.47 & 35.75 & 8.22 & 37.42 & 7.79 & 37.81 & 7.29 & .478 & .493 & .01 \\
\hline Soc & 2.79 & 2.13 & 5.25 & 2.83 & 2.31 & 1.74 & 2.50 & 2.28 & 9.16 & .004 & .16 \\
\hline Pro & 9.00 & 4.20 & 9.42 & 5.78 & 7.58 & 4.50 & 5.58 & 3.63 & 2.58 & .114 & .05 \\
\hline
\end{tabular}

$*_{n}=24$. There are five missing participants due to personal reasons and one participant did not complete the whole questionnaire

$* * n=26$. There are three missing participants, because they did not complete the whole questionnaire

***Att attitude, PCK pedagogical content knowledge, Con conceptual SMK, Epi epistemic SMK, Soc social SMK, Pro procedural SMK 
on attitude, $t(23)=-7.25, p<0.001$, PCK, $t(23)=-10.36, p<0.001$, conceptual SMK, $t(23)=-6.37, p<0.001$, and social SMK, $t(23)=-3.62, p=0.001$. However, the paired $t$ tests of the epistemic SMK, $t(23)=.51, p=.614$, and the procedural SMK, $t(23)=-.34$, $p=.735$, showed no significant difference between the pretest and posttest. As expected, the paired $t$ tests of the control group showed no differences between the pretest and posttest on attitude, $t(25)=1.55, p=.133$, PCK, $t(25)=-.55, p=.587$, conceptual SMK, $t(25)=.59$, $p=.560$, social SMK, $t(25)=-.54, p=.593$, and epistemic SMK, $t(25)=-.48, p=.637$, although the control group decreased in procedural SMK, $t(25)=2.20, p=.037$.

\section{Perceived Changes in SMK of the Experimental Group}

The significant improvements of the experimental group from pretest to posttest on conceptual SMK and social SMK were confirmed by participants' own perceived improvements measured by five-point Likert items ranging from 1 (totally disagree) to 5 (totally agree) and open questions. The mean scores of participants on the Likert items of these variables were 4.21 $(S D=.78)$ and $3.78(S D=.80)$, which indicated their perceived positive changes on conceptual SMK and social SMK after taking part in the TPD programme. The perceived changes on the epistemic and procedural SMK differed from the quantitative results described in the previous paragraphs and will be explained hereafter.

The experimental group scored a mean of $3.91(S D=1.00)$ on the five-point Likert scale of perceived gains in epistemic SMK by participating in the TPD programme, which implies a sufficient perceived influence of the course on epistemic SMK. However, in their explanations, participants did not relate to the importance of creativity during the inquiry process, the tentativeness of scientific knowledge, or the difference between observations and inferences, which were part of the epistemic SMK questionnaire. Instead, they mentioned general improvements in their understanding of the generation of scientific knowledge, included perception and action in their answers, referred to course materials in general or videos that clarified epistemic knowledge, or focused on understanding the phases of inquiry.

The quantitative posttest on procedural SMK did not reveal a significant difference in comparison with the pretest. However, participants scored a mean of $4.30(S D=1.02)$ on the five-point Likert scale, which implies high perceived gains in procedural SMK. The perceived procedural SMK of these participants focused primarily on positive changes in their knowledge about formulating a research question, which was not part of the quantitative test on procedural SMK.

\section{Intentions to Sustain IBSE in Classroom Practice}

Most participants (23 out of 24) intended to guide inquiry-based projects in their classrooms more often: "Yes, at least one project each school year" and "Yes, inquiry-based learning is going to be included in our school plan 2015 - 2019". These 23 participants also planned to or had already motivated colleagues to guide inquiry-based projects in their own classrooms: "Yes, pupils have given a presentation of their investigation to the team members. The team was enthusiastic about this" and "Yes, the team will be informed about this course and the lessons in the classroom during the next seminar". Of the 23 participants that were enthusiastic about the implementation of inquiry-based learning in their own schools, 11 participants had already made specific appointments about inquiry-based learning: "There will be a study group and project plan about discovery- and inquiry-based learning. A scientific attitude and 
inquiry-based learning will be topics for the upper primary school pupils in the following school year".

\section{Key Components of the TPD}

To understand the elements of the programme that influenced the results, participants of the experimental group were asked whether the following elements contributed to perceived changes in their SMK, PCK, and attitude: understanding hard and soft scaffolds; implementing the inquiry-based lesson module in participants' own classroom; and the exchange of ideas, lesson preparations, and classroom experiences with other participants.

The hard scaffolds contributed to perceived changes in SMK, PCK, and attitude with scores on the five-point Likert scale ranging from 4.25 to 4.30. Apart from 2 participants who did not answer the open question, all 22 participants gave positive comments about the hard scaffolds. Participants commented "Hip, hip, hooray for the question machine, the question wall, the poster with inquiry phases!" and "The scaffolds have helped me to understand and transfer the knowledge/pedagogy of inquiry-based learning. It makes it easier to teach, which makes it more enjoyable".

The soft scaffolds contributed less to changes in knowledge and attitude. Scores on the five-point Likert items ranged from 3.42 to 3.52 . Soft scaffolds were mostly discussed during the fourth course meeting whereas hard scaffolds were addressed intensively throughout the course. Three participants mentioned they already had knowledge about soft scaffolds, and eight participants added that they were more aware of using soft scaffolds after the TPD. They commented "This [soft scaffolds] increased my awareness about how I can help pupils when they have questions. It is nice to be aware of that again" and "I increased my awareness to help pupils by asking them questions. No assumptions and not providing answers, just asking questions". Six participants perceived gains in their ability to guide pupils whereas three participants mentioned that soft scaffolding was difficult for them. The remaining four participants did not comment on soft scaffolds or had not practised these in their classrooms.

The exchange of ideas, materials, and experiences with other participants was perceived to contribute to teachers' changes in knowledge and attitude with scores on the five-point Likert scale ranging from 3.58 to 3.75 . Nineteen participants were positive about the exchange of ideas and experiences. Participants commented, for example "It is nice to exchange experiences and tips with other participants. Others also increased my enthusiasm" and "It is good and informative to hear methods/experiences of others to gain new ideas". However, four of these participants mentioned that they did not use the online platform much and were mostly enthusiastic about exchanging experiences during the course meetings of the TPD. Another participant explained that classroom experiences themselves were more valuable than exchanging these with other participants. The remaining four participants did not give an opinion about the exchange of ideas and experiences.

Finally, participants perceived the implementation of the classroom inquiry project to increase their SMK, PCK, and attitude with scores on the five-point Likert scale ranging from 3.96 to 4.18 . Although three participants mentioned difficult parts of the classroom inquiry project, 16 others provided positive comments about the implementation of inquiry-based learning in their own classrooms. They commented, for example "Applying the theory in practice helps to get acquainted with inquiry-based learning" and "Implementing [the inquiry-based lesson module] provides positive experiences when it 
is that well prepared as by participating in this course". The five remaining participants did not provide an answer to this open question.

\section{Discussion}

The TPD programme in the current study is based on a pedagogical framework of inquiry phases and domains of scientific knowledge (Van Uum et al. 2016) combined with hard and soft scaffolds (Van Uum et al. 2017). Our study shows that primary school teachers' SMK, PCK, and attitude towards IBSE can be improved by systematically addressing phases of inquiry combined with domains of scientific knowledge and corresponding scaffolds. In each course meeting of the TPD programme, participants retrieved and elaborated their knowledge about the inquiry phases, domains of scientific knowledge, and hard and soft scaffolds. They evaluated classroom videos of each phase of inquiry and discussed the teacher's role in supporting pupils during their inquiry process. In addition, they determined learning goals for pupils and discussed pupils' potential difficulties in each inquiry phase. An inquiry-based lesson module based on the framework and scaffolds was prepared and planned. By applying the pedagogical framework and scaffolds in their classrooms, the teachers were able to support their pupils in each phase of inquiry.

Our study demonstrated the usefulness of scaffolds during open inquiry and is in line with the results of Van der Valk and De Jong (2009). They found that tools to improve understanding of open inquiry for teachers could also be used to support pupils' understanding of the inquiry process. In our study, the scaffolding tools developed to support pupils' inquiries were useful for their teachers as well to understand open inquiry and difficulties that pupils face during the inquiry process.

\section{Crucial Components of Professional Development}

In correspondence with the study of Van Driel et al. (2012), we addressed six components of effective TPD in our programme. We focused on improving the SMK, PCK, and attitude of the participating teachers towards IBSE by implementing a pedagogical framework of inquiry phases and domains of scientific knowledge combined with scaffolds. In addition to a reasonable duration, sustainability, and school organisational conditions, such as availability of time and resources, we addressed the components of active and collaborative learning, and coherence within TPD. The latter components will be discussed hereafter. Throughout our TPD programme, coherence was achieved by continuously addressing the inquiry phases combined with the four domains of scientific knowledge and corresponding scaffolds. Furthermore, teachers implemented our pedagogical framework and scaffolds by guiding an inquiry-based lesson module in their own classrooms. In addition, active learning was promoted by collaborative evaluation of classroom videos and reflection on hands-on activities.

These features of our TPD are in line with the study of Clarke and Hollingsworth (2002) who developed a model of professional growth in which different elements were connected by enacting and reflecting on TPD. These elements comprised an external stimulus, such as information and/or support, a focus on teachers' knowledge and attitude, professional experimentation in teachers' own classrooms, and observing how pupils react to the changes in classroom practice. Our study underlines the importance of these 
elements to be included in TPD with the aim of increasing teachers' SMK, PCK, and attitude towards inquiry-based learning.

\section{Focus on the Pedagogical Framework and Scaffolds to Improve SMK, PCK and Attitude}

In the current study, the teachers of the experimental group improved their PCK, attitude, and conceptual and social SMK about IBSE while the control group showed no significant differences on these variables. The epistemic and procedural SMK of the experimental group did not improve significantly compared to the control group. These results will be clarified here.

PCK Participants improved their own knowledge about facilitating inquiry-based learning by discussing hard and soft scaffolds and composing lesson plans during the TPD programme meetings, and by implementing the scaffolds in their own classrooms. In this way, they were enabled to make connections between their own acquired knowledge and the understanding of their pupils of inquiry-based learning. This finding corresponds with the study of Brand and Moore (2011) who found that teachers learned by designing and implementing inquiry-based lessons, and by reflecting on and evaluating classroom experiences. In our study, discussing how to implement hard and soft scaffolds in teachers' own classrooms, and the evaluation of the implemented scaffolds, contributed to their PCK. Therefore, we recommend teacher trainers to address the implementation of hard and soft scaffolds in TPD programmes about IBSE.

Conceptual SMK In our TPD programme, the conceptual SMK focused on the relations between perception and action. The teachers made a mindmap, participated in hands-on activities, and reflected on these by means of the hard scaffold "combining theory and practice". Finally, they differentiated between acquired knowledge and remaining questions when formulating initial questions to attach to the hard scaffold "question wall". The importance of active hands-on learning corresponds with the study of Niemi and Nevgi (2014) who showed that research studies and active learning, such as constructing, sharing, and reflecting on knowledge, influenced pre-service teachers' professional competences. Our study contributes to this finding by combining hands-on activities with scaffolds to stimulate teachers' understanding of and reflection about the concepts of perception and action. We, therefore, recommend including elements of active hands-on learning combined with scaffolds within teacher professional development about IBSE.

Social SMK Participants in the current study improved their social SMK by discussing and doing exercises related to hard scaffolds about collaboration and effective communication within a research group and research presentations. In addition to scaffolds regarding conceptual understanding and epistemic explanations of scientific findings (Sandoval and Reiser 2004), and scaffolds to enhance conceptual understanding, procedural knowledge, and reflective competence (Reid et al. 2003), the current study shows that social hard scaffolds can improve understanding of the inquiry process. We recommend teacher trainers to use the four domains of scientific knowledge in the current study (conceptual, epistemic, social, and procedural) as a base for developing hard scaffolds to professionalise primary school teachers in IBSE. 
Attitude During the TPD programme, participants discussed the importance of IBSE, experienced and appreciated scaffolds and activities that could be directly used in their own classrooms, and reflected on improvements in their attitude towards IBSE. The importance of explicit attention to primary school teachers' attitude is confirmed by the study of Van Aalderen-Smeets and Walma van der Molen (2015). They showed that activities, such as formulating a research question combined with reflection on teachers' attitude, contributed to a positive attitude towards (teaching) science and stimulated teachers to increase the amount of science in their classrooms. The TPD programme of Van Aalderen-Smeets and Walma van der Molen involved about 53-58 h. The teachers in the experimental group of the current study spent about $45-52.5 \mathrm{~h}$ on their professionalisation of IBSE included guiding an inquiry-based lesson module in their own classrooms. Since we were able to improve teachers' PCK and SMK in addition to their attitude, we recommend teacher trainers to formulate goals to improve teachers' SMK, PCK, and attitude, and to design professionalisation activities that contribute to several of these goals simultaneously.

Epistemic SMK The importance of creativity during the inquiry process, the tentativeness of research results, and the difference between observations and inferences were addressed in the TPD programme by evaluating a video and doing exercises that were part of hard scaffolds on these topics. However, the amount of time spent on promoting knowledge about these NOS aspects was limited. Since an implicit approach to teaching NOS aspects is less effective (Khishfe and Abd-El-Khalick 2002; Murphy et al. 2007a), we should have explicated these NOS aspects throughout the TPD programme. This is a limitation of our study. In addition, Akerson and Hanuscin (2007), who studied teachers' NOS understandings and their ability to teach NOS, emphasised that improving knowledge about NOS takes time. Therefore, we recommend including several scaffolds and activities in TPD about IBSE focused explicitly on developing knowledge on NOS aspects and to provide follow-up workshops in which changes in NOS views can be supported.

Procedural SMK During the TPD programme, the procedural SMK of participants was addressed in exercises related to hard scaffolds. For example, participants formulated research questions supported by the hard scaffold "question machine". For each component of procedural knowledge, separate exercises were provided. Although participants filled in part of a research plan, they did not design their own investigation as is measured by the Diet Cola test (Fowler 1990). Consequently, their procedural SMK score did not improve between pre- and posttest. This could be considered a limitation of our study. To promote participants' procedural SMK, we recommend including designing (and conducting) a small investigation by participants as part of IBSE professionalisation to apply the knowledge they acquired by means of the hard scaffolds. This recommendation is supported by Capps and Crawford (2013) who centralised scientific investigations conducted by participants in a TPD programme about inquiry-based learning. Although Capps and Crawford did not test participants' procedural SMK, participants had increased their views of inquiry after the professionalisation.

\section{Limitations and Recommendations}

In addition to the limitations in our TPD programme regarding the attention to epistemic and procedural SMK mentioned in the previous paragraphs, we relied on self-report data when 
measuring the PCK of the experimental and control group, and the perceived changes of the experimental group. We asked participants about their perceived changes to gain insight into their own opinions about these changes. To measure teachers' PCK, there was limited amount of time available, because we also wanted to measure their SMK of the four domains of scientific knowledge and their attitude. Therefore, we excluded, for example interviews or observations as measurement instruments. As it is difficult to construct a test to measure teachers' PCK with multiple-choice items (Rohaan et al. 2009), we chose self-report data to measure teachers' PCK. Although it is possible that the participants provided answers that they considered socially acceptable instead of their own opinions, we are confident that this data reflects the PCK of participants when we take into account their comments during TPD course meetings and their reflections after each inquiry-based lesson they guided in their own classrooms.

In the current study, we investigated the impact of a TPD programme about inquiry-based learning on the knowledge and attitude of primary school teachers. A recommendation for future research is to investigate whether teachers actually change their teaching practice and are able to support inquiry-based learning after their participation in a TPD programme. In addition, we recommend measuring changes in pupils' knowledge and skills before and after their teachers implement elements of an inquiry-based TPD programme in their classrooms to determine whether TPD has an effect on pupils' achievements. In the current study, we included in-service primary school teachers. For future research, we recommend including pre-service teachers as well, to establish whether both pre-service and in-service teachers can be professionalised equally.

The pedagogical framework of inquiry phases combined with domains of scientific knowledge and corresponding scaffolds that we used to professionalise primary school teachers, improved their SMK, PCK, and attitude towards IBSE. Discussing and implementing scaffolds, facilitating activities in which teachers could construct their own knowledge, and coherence between the TPD programme and classroom practice enabled teachers to apply their acquired knowledge and enjoy guiding an inquiry-based lesson module in their own classrooms.

Funding Information Royal Netherlands Academy of Arts and Sciences.

Open Access This article is distributed under the terms of the Creative Commons Attribution 4.0 International License (http://creativecommons.org/licenses/by/4.0/), which permits unrestricted use, distribution, and reproduction in any medium, provided you give appropriate credit to the original author(s) and the source, provide a link to the Creative Commons license, and indicate if changes were made.

Publisher's Note Springer Nature remains neutral with regard to jurisdictional claims in published maps and institutional affiliations.

\section{References}

Adams, C. M., \& Callahan, C. M. (1995). The reliability and validity of a performance task for evaluating science process skills. Gifted Child Quarterly, 39(1), 14-20.

Akerson, V. L., \& Hanuscin, D. L. (2007). Teaching nature of science through inquiry: results of a 3-year professional development program. Journal of Research in Science Teaching, 44(5), 653-680.

Alexandrov, A. V., \& Hennerici, M. G. (2013). How to prepare and deliver a scientific presentation. Cerebrovascular diseases, 35, 202-208.

Alfieri, L., Brooks, P. J., Aldrich, N. J., \& Tenenbaum, H. R. (2011). Does discovery-based instruction enhance learning? Journal of Educational Psychology, 103(1), 1-18. 
Aydeniz, M., \& Brown, C. L. (2010). Enhancing pre-service elementary school teachers' understanding of essential science concepts through a reflective conceptual change model. International Electronic Journal of Elementary Education, 2(2), 1-22.

Baarda, D. B., De Goede, M. P. M., \& Teunissen, J. (2001). Basisboek kwalitatief onderzoek. Praktische handleiding voor het opzetten en uitvoeren van kwalitatief onderzoek. [Basic book qualitative research. Practical manual to design and conduct qualitative research.] Groningen: Stenfert Kroese.

Bleicher, R. E., \& Lindgren, J. (2005). Success in science learning and preservice science teaching self-efficacy. Journal of Science Teacher Education, 16(3), 205-225.

Brand, B. R., \& Moore, S. J. (2011). Enhancing teachers' application of inquiry-based strategies using a constructivist sociocultural professional development model. International Journal of Science Education, 33(7), 889-913.

Bransford, J. D., Brown, A. L., \& Cocking, R. R. (1999). How people learn: Brain, mind, experience, and school. Washington, DC: National Academy Press.

Braund, M., \& Driver, M. (2005). Pupils' perceptions of practical science in primary and secondary school: implications for improving progression and continuity of learning. Educational Research, 47(1), 77-91.

Capps, D. K., \& Crawford, B. A. (2013). Inquiry-based professional development: what does it take to support teachers in learning about inquiry and nature of science? International Journal of Science Education, 35(12), 1947-1978.

Clarke, D., \& Hollingsworth, H. (2002). Elaborating a model of teacher professional growth. Teaching and Teacher Education, 18, 947-967.

Durant, J. R. (1993). What is scientific literacy? In J. R. Durant \& J. Gregory (Eds.), Science and Culture in Europe (pp. 129-137). London: Science Museum.

Duschl, R. A. (2008). Science education in three-part harmony: balancing conceptual, epistemic, and social learning goals. Review of Research in Education, 32(1), 268-291.

Elizabeth, T., Ross Anderson, T. L., Snow, E. H., \& Selman, R. L. (2012). Academic discussions: an analysis of instructional discourse and an argument for an integrative assessment framework. American Educational Research Journal, 49(6), 1214-1250.

Ely, D. P. (1990). Conditions that facilitate the implementation of educational technology innovations. Educational Technology, 39(6), 23-27.

Fowler, M. (1990). The diet cola test. Science Scope, 13(4), 32-34.

Fullan, M. (2007). The new meaning of educational change (3rd ed.). New York: Teachers College Press.

Furtak, E. M., Seidel, T., Iverson, H., \& Briggs, D. C. (2012). Experimental and quasi experimental studies of inquiry-based science teaching: a meta-analysis. Review of Educational Research, 82(3), 300-329.

Gibson, H. L., \& Chase, C. (2002). Longitudinal impact of an inquiry-based science program on middle school students' attitudes toward science. Science Education, 86(5), 693-705.

Harlen, W., \& Holroyd, C. (1997). Primary teachers' understanding of concepts of science: impact on confidence and teaching. International Journal of Science Education, 19(1), 93-105.

Johnson, D. W., \& Johnson, R. T. (2009). An educational psychology success story: social interdependence theory and cooperative learning. American Educational Research Association, 38(5), 365-379.

Khishfe, R., \& Abd-El-Khalick, F. (2002). Influence of explicit and reflective versus implicit inquiry-oriented instruction on sixth graders' views of nature of science. Journal of Research in Science Teaching, 39(7), 551-578.

Lajoie, S. P. (2005). Extending the scaffolding metaphor. Instructional Science, 33, 541-557.

Landis, J. R., \& Koch, G. G. (1977). The measurement of observer agreement for categorical data. Biometrics, 33(1), 159-174.

Liang, L. L., Chen, S., Chen, X., Kaya, O. N., Adams, A. D., Macklin, M., \& Ebenezer, J. (2008). Assessing preservice elementary teachers' views on the nature of scientific knowledge: a dual-response instrument. Asia-Pacific Forum on Science Learning and Teaching, 9(1), 1-19.

Lotter, C. R., Thompson, S., Dickenson, T. S., Smiley, W. F., Blue, G., \& Rea, M. (2018). The impact of a practice-teaching professional development model on teachers' inquiry instruction and inquiry efficacy beliefs. International Journal of Science and Mathematics Education, 16(2), 255-273.

Mercer, N., Dawes, L., Wegerif, R., \& Sams, C. (2004). Reasoning as a scientist: ways of helping children to use language to learn science. British Educational Research Journal, 30(3), 359-377.

Minner, D. D., Levy, A. J., \& Century, J. (2010). Inquiry-based science instruction - what is it and does it matter? Results from a research synthesis years 1984 to 2002. Journal of Research in Science Teaching, 47(4), 474 496.

Murphy, C., \& Beggs, J. (2003). Children's perceptions of school science. School Science Review, 84(308), 109-116.

Murphy, C., Kilfeather, P., \& Murphy, C. (2007a). An exploration of issues surrounding teaching the nature of science to pre-service primary school teachers. Irish Educational Studies, 26(1), 27-38.

Murphy, C., Neil, P., \& Beggs, J. (2007b). Primary science teacher confidence revisited: ten years on. Educational Research, 49(4), 415-430. 
Murphy, C., Smith, G., Varley, J., \& Razi, O. (2015). Changing practice: an evaluation of the impact of a nature of science inquiry-based professional development programme on primary teachers. Cogent Education, 2(1), $1-19$.

National Research Council. (1996). National Science Education Standards. Washington, DC: National Academy Press.

National Science Teachers Association. (2000). NSTA Position Statement. The Nature of Science. http://www. nsta.org/about/positions/natureofscience.aspx. Accessed 11 Feb 2018.

Niemi, H., \& Nevgi, A. (2014). Research studies and active learning promoting professional competences in Finnish teacher education. Teaching and Teacher Education, 43, 131-142.

Peeters, M., Meijer, W., \& Verhoeff, R. (2014). Wetenschappelijke doorbraken de klas in! Waarnemen en bewegen, Onder invloed en Gevaarlijke ideeën. [Scientific breakthroughs inside the classroom! Perception and action, Addition, and Dangerous opinions]. Nijmegen: Wetenschapsknooppunt Radboud Universiteit.

Reid, D. J., Zhang, J., \& Chen, Q. (2003). Supporting scientific discovery learning in a simulation environment. Journal of Computer Assisted Learning, 19, 9-20.

Rohaan, E. J., Taconis, R., \& Jochems, W. M. G. (2009). Measuring teachers' pedagogical content knowledge in primary technology education. Research in Science \& Technology Education, 27(3), 327-338.

Rohaan, E. J., Taconis, R., \& Jochems, W. M. G. (2010). Reviewing the relations between teachers' knowledge and pupils' attitude in the field of primary technology education. International Journal of Technology and Design Education, 20(1), 15-26.

Sandoval, W. A., \& Reiser, B. J. (2004). Explanation-driven inquiry: integrating conceptual and epistemic scaffolds for scientific inquiry. Science Education, 88(3), 345-372.

Saye, J. W., \& Brush, T. (2002). Scaffolding critical reasoning about history and social issues in multimediasupported learning environments. Educational Technology Research and Development, 50(3), 77-96.

Schroeder, C. M., Scott, T. P., Tolson, H., Huang, T.-Y., \& Lee, Y.-H. (2007). A meta-analysis of national research: effects of teaching strategies on student achievement in science in the United States. Journal of Research in Science Teaching, 44(10), 1436-1460.

Shulman, L. S. (1987). Knowledge and teaching: foundations of the new reform. Harvard Educational Review, $57(1), 1-22$.

Simons, K. D., \& Klein, J. D. (2007). The impact of scaffolding and student achievement levels in a problembased learning environment. Instructional Science, 35, 41-72.

Smit, J., Eerde, H. A. A., \& Bakker, A. (2013). A conceptualisation of whole-class scaffolding. British Educational Research Journal, 39(5), 817-834.

Techniekpact. (2013). Nationaal Techniekpact 2020 [National Technologypact 2020]. http://www.techniekpact. nl/cdi/files/f1441a07a7dab41382fd20095b16c618ad14773c.pdf. Accessed 11 February 2018.

Van Aalderen-Smeets, S., \& Walma van der Molen, J. (2013). Measuring primary teachers' attitudes toward teaching science: development of the Dimensions of Attitude toward Science (DAS) instrument. International Journal of Science Education, 35(4), 577-600.

Van Aalderen-Smeets, S. I., \& Walma van der Molen, J. H. (2015). Improving primary teachers' attitudes toward science by attitude-focused professional development. Journal of Research in Science Teaching, 52(5), 710734.

Van de Pol, J., Volman, M., Oort, F., \& Beishuizen, J. (2014). Teacher scaffolding in small group work: an intervention study. Journal of the Learning Sciences, 23(4), 600-650.

Van der Valk, T., \& De Jong, O. (2009). Scaffolding science teachers in open inquiry teaching. International Journal of Science Education, 31(6), 829-850.

Van Driel, J. H., Verloop, N., \& De Vos, W. (1998). Developing science teachers' pedagogical content knowledge. Journal of Research in Science Teaching, 35(6), 673-695.

Van Driel, J. H., Meirink, J. A., Van Veen, K., \& Zwart, R. C. (2012). Current trends and missing links in studies on teacher professional development in science education: a review of design features and quality of research. Studies in Science Education, 48(2), 129-160.

Van Graft, M., \& Kemmers, P. (2007). Onderzoekend en ontwerpend leren bij natuur en techniek. Basisdocument over de didactiek voor onderzoekend en ontwerpend leren in het primair onderwijs. [Inquiry- and designbased learning in science and technology. Central document about the didactics of inquiry- and design-based learning in primary education]. Den Haag: Stichting Platform Bèta Techniek.

Van Uum, M. S. J., Verhoeff, R. P., \& Peeters, M. (2016). Inquiry-based science education: towards a pedagogical framework for primary school teachers. International Journal of Science Education, 38(3), $450-469$.

Van Uum, M. S. J., Verhoeff, R. P., \& Peeters, M. (2017). Inquiry-based science education: scaffolding pupils' self-directed learning in open inquiry. International Journal of Science Education, 39(18), 2461-2481. 
Windschitl, M. (2003). Inquiry projects in science teacher education: what can investigative experiences reveal about teacher thinking and eventual classroom practice? Science Education, 87(1), 112-143.

Yoon, H.-G., Joung, Y. J., \& Kim, M. (2012). The challenges of science inquiry teaching for pre-service teachers in elementary classrooms: difficulties on and under the scene. Research in Science Education, 42(3), 589608.

Zion, M., Cohen, S., \& Amir, R. (2007). The spectrum of dynamic inquiry teaching practices. Research in Science Education, 37(4), 423-447. 